Dicenda. Estudios de lengua y literatura españolas

ISSN-e: 1988-2556

http://dx.doi.org/10.5209/DICE.62152

\title{
Enfrentamientos entre reinas y validos en el teatro áureo español
}

\author{
Ana Zúñiga Lacruz ${ }^{1}$
}

Recibido: 14 de diciembre de 2015 / Aceptado: 23 de septiembre de 2018

Resumen. En el teatro español del Siglo de Oro son muy frecuentes las reflexiones sobre el ejercicio del poder. Por ello, no es extraño que por las tablas desfilen personajes como el rey, la reina y los validos. Estos dos últimos -soberana y privado-, en ocasiones, son protagonistas de relaciones muy tirantes, o bien por motivos gubernamentales (ambición de poder), o bien por asuntos amorosos.

Palabras clave: Teatro; Siglo de Oro; reina; valido.

\section{[en] Confrontations between Queens and favourites in Spanish Golden Theatre}

Abstract. The playwrights of the Spanish Golden Age Theatre reflect about power and politics, so there are many characters such as the king, the queen and favourites. These last ones are protagonists of very tense situations, because of the government-yearning of power- or because of love.

Keywords: Theatre; Golden Age; queen; favourite.

Sumario: 1. Privados pérfidos; 2. Privados nobles; 2.1 Reina insidiosa que quiere romper la estrecha relación entre privado y monarca; 2.2. Reina insidiosa que busca la caída del privado por despecho y celos.

Cómo citar: Zúñiga Lacruz, A. (2018). Enfrentamientos entre reinas y validos en el teatro áureo español, en Dicenda. Estudios de Lengua y Literatura Españolas, 36, 343-357.

En los textos teatrales del Siglo de Oro se examinan las realidades políticas y sociales desde dos perspectivas: positiva, al enaltecerse al poderoso y su misión encaminada a lograr el bien común, y negativa, al subrayarse los abusos del monarca y sus privados. Esta última figura, especialmente en el siglo XVII, se coloca "en el punto de mira de tratadistas y teóricos de la política, además de concentrar numerosas reacciones de súbditos y oponentes políticos" (Arellano, 1996: 43). Por ello, no es de extrañar que se convierta también en protagonista o antagonista de numerosas obras teatrales que reflexionan sobre cuestiones relacionadas con el ejercicio del poder (Roncero López, 2013: 199) y que conforman entre 1595 y 1611 la comedia de privanza. Mediante este género se teatralizan las vertiginosas subidas y caídas de privados, que permiten "exponer, criticar y resolver una de las realidades más problemáticas del día en personajes ficticios o en figuras de los tiempos lejanos de la Edad Media" (Peale, 2004: 134).

Universidad de Navarra

azlacruz@unav.es 
En estas comedias de privanza, en algunas ocasiones el valido es presentado como un personaje intrigante y ambicioso, que se aprovecha de la confianza del monarca para medrar; en otras ocasiones, el privado es un personaje noble que padece injustamente las insidias cortesanas, motivadas, en gran medida, por la envidia ${ }^{2}$.

Estos dos personajes antitéticos del privado no interactúan solo con el rey, sino que también se relacionan con soberanas -figuras poderosas de peso en el teatro áureo- que desempeñan la función política de consorte. Con ellas el privado puede mantener relaciones amistosas o, por el contrario, ásperas. En este último caso, se distinguen dos variantes: una es la que presenta a un privado pérfido o a los favoritos del monarca procurando la caída en desgracia de la reina para mantenerse -o progresar- en la esfera del poder; otra es la del buen privado atacado por la reina, o bien hastiada por la influencia que ejerce sobre su esposo, o bien herida por la indiferencia amorosa que muestra el favorito hacia ella.

A la primera variante se ajustan obras como La mejor luna africana (1637-1643), de Antonio Martínez de Meneses y otros ingenios ${ }^{3}$, Santa Isabel, reina de Portugal (ca. 1625), de Rojas Zorrilla, y La adúltera virtuosa (ca. 1603), de Mira de Amescua.

El primer grupo de la segunda variante -reina insidiosa que pretende evitar la influencia del favorito sobre el monarca- incluye La adversa fortuna de don Álvaro de Luna (1615-1621), de Mira de Amescua, Doña Beatriz de Silva (1619-1621), de Tirso de Molina, La fundadora de la Santa Concepción. Primera y segunda parte (1620-1627), de Blas Fernández de Mesa, y, finalmente, El milagro de los celos y don Álvaro de Luna (anterior a 1632), atribuida a Lope. Todas estas piezas presentan como personaje regio femenino a la histórica Isabel de Portugal y Castilla, que desea deshacerse del influyente privado Álvaro de Luna. También busca la caída del favorito la reina Catalina -trasunto histórico de la soberana Leonor de Castilla- en la lopesca Las mudanzas de Fortuna (1604-1608) para lograr que su hijo medre en detrimento de su hijastro y heredero a la corona. En este grupo se puede incluir también El mayor desengaño (ca. 1621), comedia hagiográfica de Tirso, en la que una emperatriz alemana arroja del puesto de privado al futuro san Bruno.

En el segundo grupo -reina insidiosa herida por la indiferencia amorosa del privado- hay que mencionar piezas como la miramescuana El ejemplo mayor de la desdicha (1632) y Comedia nueva del perseguido (anterior a 1596), de Lope de Vega.

En las siguientes páginas me propongo trazar temas y rasgos característicos de este tipo particular de comedia de privanza en la que el interés recae en gran medida sobre la reina, figura que permite a los dramaturgos ahondar en temas tales como la honra, los celos o el ejercicio del poder femenino ${ }^{4}$.

\section{Privados pérfidos}

La obra La mejor luna africana, drama de honor conyugal, recrea un legendario episodio de falsa acusación protagonizado por el rey Chico y su esposa, nombrada

\footnotetext{
2 Envidia, fortuna, amistad, ingratitud y desengaño son los ingredientes esenciales, según Peale (2004: 137), de la comedia de privanza. Remito también a Sáez (2015: 173).

3 Sobre su autoría, se puede consultar Carrasco Urgoiti (1964).

4 Si se desea profundizar en el distinto tipo de poder que ejercen las soberanas representadas en el teatro áureo, puede consultarse Zúñiga Lacruz (2015).
} 
como Sultana (el nombre histórico que le correspondería sería Morayma, la última reina mora de Granada):

Según nos cuenta Pérez de Hita, en las guerras civiles de Granada unos enemigos de los Abencerrajes acusan a la reina Sultana de adulterio con un Abencerraje. Un pariente hace que ella escoja un campeón, el cual, ayudado por tres compañeros, mata a los calumniadores; pero uno vive lo suficiente para confesar el delito. Sultana evita ser quemada, y hay grandes fiestas (Tyler, 1967: 637).

El intrigante personaje que asume la función de calumniador en la comedia es el moro Gomel, privado que, movido por la envidia, trata por todos los medios de dar muerte al valeroso Hacén, quien goza de gran estima por parte de los soberanos granadinos, especialmente de la sultana, como rabia el intrigante cortesano: "Siempre con la reina alcanza / favor Hacén. ¡Qué rigor! / Pero de aqueste favor / sabré labrar mi venganza" (pliego B2r).

Esa venganza se consuma poco después, ya que el intrigante Gomel es el encargado de engañar al rey Chico haciéndole creer que la soberana le es infiel con Hacén: cuando el leal caballero está galanteando a la cristiana Leonor, esclava favorita de la reina, el soberano aparece en el terrero instado por Gomel y malinterpreta unas palabras de su esposa encaminadas a favorecer los amores de ambos jóvenes. Esto despierta la ira del sultán, que manda prender a Hacén -acusado también de traición a la corona- y a su mujer, a la que condena a la hoguera, ofreciéndole la posibilidad de salvar la vida si algún caballero está dispuesto a defender su inocencia batiéndose en duelo contra el acusador. La soberana mora recurre al noble cristiano don Juan, amigo de Hacén, implorándole ayuda para limpiar su honor.

Ambos caballeros, el cristiano don Juan y el moro Hacén -huido de la cárcel-, desmienten las calumnias vertidas por el privado Gomel sobre la reina al enfrentarse y derrotar al falso acusador y a sus oponentes, pertenecientes al linaje de los Muza y los alaveses ${ }^{5}$. De esta forma se produce el final feliz de restauración del orden: castigo mortal para los pecadores -el privado Gomel-y salvación para los virtuosos -Hacén y reina mora-. A esto se añade la conversión al catolicismo del moro Hacén, lo que le permite desposarse con su amada Leonor, liberada por la sultana en agradecimiento a la ayuda recibida por el católico don Juan.

Por tanto, Sultana aparece en esta comedia como reina virtuosa que es falsamente acusada de adulterio por el valido Gomel con la intención de arrojar de su privanza al abencerraje Hacén, favorito de la reina, quien ha de sufrir las consecuencias del cainita deseo del moro Gomel: mancha injusta en su honor, desprecio de su marido y condena a muerte. Gracias a la intervención del noble Hacén -inclinado al cristianismo- y del caballero católico don Juan, la fama de la reina es limpiada y Sultana es restaurada en el puesto que le corresponde como consorte, al lado de su esposo, el rey Chico.

También la envidia, unida a los irracionales celos, es el motor de las alevosas acciones acometidas por el privado del rey Dionís en Santa Isabel, reina de Portugal.

Los personajes de Gomel y de Hacén encarnan, respectivamente, los linajes moros de los Gomeles y los Abencerrajes, enfrentados en las guerras civiles granadinas. En ellas también participan otros linajes moros históricos como el de los Muza, citado en el texto teatral. Para profundizar en estos enfrentamientos entre linajes moros, se puede consultar Pérez de Hita, Guerras civiles de Granada. 
Esta reina santa (Zaragoza, 1271-Estremoz [Portugal], 1336) ha pasado a la historia por su virtuosa vida (caritativa, devota y mediadora) y por soportar con paciencia las innumerables infidelidades de su antitético esposo, instigadas en la comedia por Carlos, personaje ficticio que asume la función de valido del monarca lusitano. Desde el inicio de la obra se presentan dos grupos de personajes claramente diferenciados y opuestos: uno está integrado por el monarca, quien va degradándose moralmente conforme avanza la obra, en gran medida arrastrado por su favorito, Carlos, personaje que comparte con él numerosos rasgos negativos; en el lado opuesto se sitúan la reina Isabel y su valido Ramiro. En este caso, es la soberana de Portugal quien con su ejemplo arrastra hacia la virtud a su privado ${ }^{6}$.

El soberano don Dionís, influido por su valido Carlos, reprende a su mujer en tres aspectos que contribuyen a evidenciar y reforzar el carácter humilde y servicial de la reina:

1. Alude a su vestuario "grosero" (v. 297), solicitándole que no afecte santidad y vista de acuerdo a su cargo real.

2. Menciona el temor de que Ramiro, privado de la reina, que ha viajado con ella desde Aragón, quiera hacerse con el poder: "Pues como el imperio os dejo / en vuestra mano y mandáis / igualmente en estos reinos, / vos sola llevada, vos, / de sus pensamientos necios / lo que él dispone ordenáis" (vv. 317-322).

3. Critica la afición de Isabel a dar limosnas a los pobres, mientras él vive empeñado. Así, exige a la soberana que modere su ejercicio de la caridad: "Templaos más en las acciones, / castigad vuestros defetos, / reprimid vuestra imprudencia" (vv. 360-362).

La reina replica a don Dionís apelando, primero, a Dios, y, posteriormente, a su honor y a su recta conciencia. De esta forma, intenta hacer ver a su marido lo erróneo de su juicio, fruto una vez más de la influencia negativa de un personaje de la corte -su valido Carlos-al que la soberana evita mencionar:

ISABEL Escuchando los discursos que decís -aunque no vuestros, pues no caben en los reyes tales razones-, confieso que, aunque siempre fui obediente a vuestros justos preceptos, hoy que la razón me sobra, y a vos no el conocimiento de lo que tenéis en mí, aunque tanto amor os debo, cuando sale la imprudencia a vestirse del desprecio, siendo cada voz agravio y escándalo cada afecto, echaréis de ver, señor,

\footnotetext{
6 "La acción dramática se ha ido decantando hacia un conflicto de caracteres perversos (don Carlos) y débiles (don Dionís), frente a generosos y enteros (la reina, don Ramiro)” (Pedraza Jiménez, 2005: 976-977).
} 
lo que os estimo, supuesto

que no os debo el menor cargo

de lo que argüís defectos (vv. 378-395).

A pesar de los sensatos y virtuosos contrargumentos de la soberana, el terrenal don Dionís persevera en su rechazo hacia la actitud de su esposa, basada en el ayuno, la disciplina y la limosna (vv. 846-848), y llega a creer las falsas acusaciones de adulterio por parte de Carlos -actuación similar a la del analizado Gomel de $L a$ mejor luna africana-, quien pretende hacer caer a la reina y a su valido Ramiro para manipular con más facilidad al monarca y conquistar a la dama de su enemigo: "Es que Portugal murmura / -ya que saberlo pretendes- / que Ramiro..., que la reina..., / que su amor...; pero ella viene" (vv. 1054-1057).

Carlos contribuye decisivamente al padecimiento de la soberana: primero, por la calumnia que ha vertido contra ella; segundo, por alentar la actitud lasciva de don Dionís. Este pérfido privado, ante las amonestaciones de la soberana instándole a que evite la pérdida moral de su esposo, responde con odio y amenazas, sabiéndose protegido por el soberano, que confía ciegamente en él. Ante la soberbia y vanidad de Carlos, la reina adopta una actitud humilde: "Carlos en aquesta sala / hablando consigo está. / Hoy de mi piedad verá / que a sus traiciones iguala" (vv. 2334-2337). Una vez más, este comportamiento piadoso de la soberana contrasta con el despiadado de Carlos, que llega a conseguir que el monarca dicte una sentencia de muerte contra su esposa: "Agora que estoy conmigo / prevenir es importante / con la muerte de mi esposa / la venganza de mis males" (vv. 2621-2624).

La respuesta de la reina ante esta situación vuelve a erigirla como dechado de virtudes, pues mientras que el rey pide la muerte de su mujer a instancias de Carlos, esta, a su vez, pide a Dios por la vida de su esposo:

ISABEL ¡Señor, pues que vos queréis

que yo muera en este traje

y agora en él me mudáis,

procurando adelantarme

lo futuro de las dichas

lo cierto de los males,

dejad vivir a mi esposo! (vv. 2631-2637)

Estas súplicas de Isabel son atendidas por Dios, que la protege de tal manera que queda al descubierto la falsa acusación vertida sobre ella por el intrigante privado Carlos, que es castigado al recibir la muerte en lugar del noble Ramiro.

De esta forma, se restaura el orden en palacio, presentado como lugar de traiciones y pecados: Don Dionís consigue enmendar sus pasos; la reina recupera su poder junto a su esposo en calidad de reina consorte; el virtuoso valido Ramiro se desposa con la dama amada; finalmente, el pérfido privado Carlos, ante el que la propia reina se ha arrodillado suplicando que guíe rectamente a su esposo, paga todas sus culpas recibiendo la muerte de la misma forma que pensaba dársela a Ramiro: arrojado vivo a un horno encendido.

También hallarán la muerte, por incitar a la senda del vicio al monarca, los intrigantes favoritos que intervienen en La adúltera virtuosa (ca. 1603), obra en la que se presenta un problema de honor conyugal y de falsa acusación contra la reina Catalina 
de Nápoles. El Conde y el Barón son los personajes ambiciosos y soberbios que se dedican a adular al soberano napolitano y a cumplir sus deseos para mantenerse en la esfera de poder. Así, lo animan a que dé rienda suelta a la pasión que siente por doña Juana, hermosa dama española que está desposada con el duque Mauricio, al que traman dar muerte para que la joven quede libre y pueda entregarse al monarca sin suscitar problemas de honor.

En este corrompido contexto emerge virtuosamente la reina Catalina, quien descubre los amores de su marido hacia la firme doña Juana, exaltados por los consejos de sus favoritos, Barón y Conde. La soberana, para evitar la negativa influencia de estos viles personajes sobre su esposo, decide desterrarlos, amenazándolos de muerte si no cumplen su orden. No obstante, confiados ambos en el aprecio que siente hacia ellos el rey, infravaloran a la soberana napolitana y su poder:

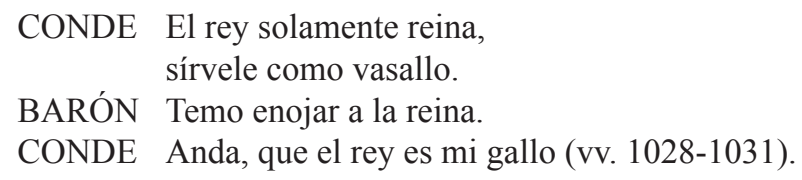

La reina, por tanto, se ve obligada a soportar la presencia de estos dos personajes en la corte hasta que se le informa del asesinato a traición del duque Mauricio. Catalina, ante este crimen, cuya autoría conoce, busca ejercer justicia y castigar las maldades de los privados de su esposo, a los que manda prender para ser ajusticiados: "Quiero llamar quien os prenda, / que habéis de morir, traidores, / aunque mi esposo os defienda. / ¡Ah, de mi guarda!” (vv. 1720-1723a).

Esta acción de la reina enoja a Barón y Conde, quienes cometen la osadía de acusarla de adúltera. La soberana, sabiendo que su esposo confía en ella y la considera mujer virtuosa, lo exhorta a castigar semejante afrenta: "A la reina han ofendido, / y a vuestra mujer; si hay ley / que no abone su partido, / o castigad como rey / o vengad como marido" (vv. 1753-1757).

Si bien en un primer momento el rey cree a su esposa, la persistencia de Barón y Conde en su acusación hace surgir sombras de duda en el monarca, que termina aceptando la versión de sus maledicentes validos tras ver cómo su esposa abraza a un hombre (en realidad, se trata de la dama doña Juana en traje varonil). El soberano, por tanto, la condena a muerte, ofreciéndole la posibilidad del perdón si algún caballero se ofrece a defender su inocencia.

La reina, a pesar de este difícil trago provocado por los favoritos de su esposo, confía en Dios: “¡Dios nunca esconde / la verdad!” (vv. 2569-2570). Y, efectivamente, así sucede: la verdad se descubre gracias al duque Mauricio - que no está muertoy al caballero Felipe, que se presentan al duelo en defensa de la reina, ensalzándola como "esposa casta y noble" (v. 2511) y obligando a los dos perversos personajes a confesar su calumnia, por la que son ajusticiados mediante garrote vil. Una vez probada la inocencia y castidad de Catalina, el rey vuelve a restaurarla en su puesto de esposa del monarca y de reina consorte: "Volved, reina, a vuestro asiento, / porque, en él, mi reino os honre" (vv. 2516-2517).

Así pues, en sintonía con lo sucedido en Santa Isabel, reina de Portugal, la reina padece por las calumnias de adulterio vertidas por los favoritos del monarca, ante los que no se humilla - como hace Isabel, en coherencia a su santidad-, sino a los que se enfrenta ordenando, primero, su destierro; posteriormente, ante el conocimiento del 
asesinato del duque, los apresa para que sean condenados a muerte. La reina Catalina emplea su poder como soberana consorte para arrestar y acusar a los favoritos del monarca; no obstante, poco después queda evidenciada la supeditación de la reina a su esposo, quien ostenta el poder supremo y confía en ambos personajes. La estrecha unión de estos con el soberano, alcanzada a través de las alabanzas y el cumplimiento de sus deseos, les sirve de defensa para desobedecer las órdenes de la soberana y atreverse a acusarla falsamente. Gracias a la intervención de unos personajes nobles de la corte, sale a la luz la verdad, lo que conlleva la restauración de la reina en su poder y la caída de los favoritos, que son condenados a muerte y ejecutados en pago a sus maldades.

Así pues, a modo de resumen, se pueden mencionar las siguientes concomitancias de estas tres obras analizadas:

- Se producen enfrentamientos por cuestiones morales -que repercuten inevitablemente en el ámbito político- entre las reinas consortes virtuosas y los pérfidos validos de sus esposos y monarcas.

- Los privados del monarca buscan la caída de la reina para medrar-Gomel en La mejor luna africana - o para mantenerse en el poder -Carlos en Santa Isabel, reina de Portugal, y Barón y Conde en La adúltera virtuosa-:

- En el primer caso, Sultana muestra su inclinación hacia Hacén, moro noble perteneciente a los Abencerraje, linaje enemigo de Gomel, lo que despierta la envidia de este. Acusar a la reina de amores con Hacén supone para Gomel, primero, que el sultán aumente su confianza en él, ya que le desvela las intrigas palaciegas; segundo, tener campo libre para asumir de manera exclusiva la privanza, al desaparecer Hacén y la sultana, que es su principal valedora.

- Por su parte, en la obra protagonizada por santa Isabel, Carlos desea aumentar su poder lisonjeando al monarca y halagando sus oídos, por lo que lo insta a cumplir todas sus apetencias y a satisfacer sus instintos. Esto es algo a lo que se opone la reina santa, por lo que se gana el desprecio del valido. De ahí su acusación contra la soberana, mediante la que también cumple un doble objetivo: deshacerse de quien se opone a su estrategia para mantenerse en el poder y de quien es la valedora de Ramiro, noble a quien ama la mujer de quien él está enamorado. Si la reina cae, también Ramiro, por lo que podrá desposarse con la mujer amada.

- Por último, en La adúltera virtuosa, los favoritos del monarca persiguen la muerte de la soberana para mantenerse en el poder, ya que la reina se opone a su estrategia, que es la misma que la de Carlos: la lisonja constante hacia el monarca, al que apoyan en todas sus actuaciones, por muy depravadas e injustas que sean.

- La manera de acabar con la soberana es la falsa acusación de adulterio: en los tres casos, los favoritos difaman a la reina tachándola de infiel. El monarca confía en ellos y condena a muerte a la soberana. Son personajes nobles de la corte los que consiguen evitar la muerte de la reina y restaurar su fama.

- El final de los validos es siempre el mismo: la muerte. Solo difiere la forma: en La mejor luna africana, Gomel muere en el duelo contra Hacén y el caballero católico Juan. Poco antes de morir, el moro traidor confiesa su 
calumnia. En Santa Isabel, reina de Portugal, Carlos es arrojado al fuego en lugar de Ramiro, a quien estaba destinado ese luctuoso fin. En La adúltera virtuosa, Barón y Conde son los únicos que mueren, a garrote vil, por orden del monarca.

\section{Privados nobles}

Hay obras, como se apuntaba más arriba, en las que el papel de personaje intrigante es asumido por la soberana, quien hace padecer al noble privado, o bien por envidia, o bien por despecho y celos.

\subsection{Reina insidiosa que quiere romper la estrecha relación entre privado y monarca}

Uno de los ejemplos exponenciales de soberana intrigante que persigue la caída en desgracia del favorito del monarca es la histórica Isabel de Avis y Braganza (14281496), infanta de Portugal, que se convierte en reina consorte de Castilla por su matrimonio con Juan II tras enviudar este de su primera esposa, doña María, madre del futuro Enrique IV. De esta unión nacen Isabel la Católica y Alfonso, quien fallece a los 15 años. Isabel de Portugal, que sufre profundos celos a causa de Beatriz de Silva -una de sus hermosas damas, que parece despertar el interés del monarca-, se muestra siempre muy interesada en los asuntos políticos y mantiene una tensa relación con el condestable Álvaro de Luna, en cuya caída y condena a muerte influye de manera decisiva.

Estos hechos se reflejan en La adversa fortuna de don Álvaro de Luna: Mira de Amescua hace hincapié en las intrigas y envidias de la corte que llevan al privado hasta el patíbulo, abandonado por todos aquellos a los que había ayudado en algún momento, incluida la reina Isabel, a la que había logrado entronizar por su estrecha amistad con don Juan II de Castilla. Efectivamente, debido a la obstinación de don Álvaro y por respeto a su amistad, el monarca castellano decide aceptar el matrimonio que el condestable le propone con Isabel de Portugal (vv. 1687-1688). Sin embargo, la reacción de esta hacia don Álvaro no es de gratitud, sino de animadversión. Así se evidencia, por ejemplo, al rechazar la reina interceder por él ante las críticas de otros cortesanos: "Sed, maestre, buen vasallo, / y eso volverá por vos" (vv. 2240-2241).

Poco después, Isabel se niega a reconocer la deuda que tiene con don Álvaro de Luna por haberla convertido en soberana de Castilla y muestra sus simpatías hacia los enemigos que lo acusan: "Que reina por su orden fui / pretende, y es gran rigor / el tener un acreedor / siempre delante de mí" (vv. 2585-2588). Por ello, termina pidiendo a su marido que condene a muerte al condestable.

De esta forma, si al inicio de la obra era don Álvaro de Luna quien exhortaba al rey a desposarse con Isabel para convertirla en reina, ahora es esta la que desprecia al condestable alentando a su esposo - que actúa siempre sometido a la voluntad de ambos- a que firme la sentencia de muerte: "Señor, / ¿valor falta en vuestros brazos / para tener una pluma / y un papel que es justo? Agravio / hacéis a vuestra justicia" (vv. 2751b-2755). Así pues, es la reina la que exhorta al rey a olvidarse de ejercer clemencia y a ejecutar la pena capital. Ante la actitud dubitativa de su esposo a 
firmar, la reina "le va llevando el brazo para que firme" (acot. al v. 2771b), evidenciándose de esta manera el papel decisivo que desempeña la soberana en la caída del condestable: "Así / moverás, señor, el brazo" (vv. 2771b-2772). Al mover el brazo de su esposo para firmar el mortal dictamen, puede considerarse que Isabel es la principal ejecutora de la muerte del condestable.

Esta ingratitud de la reina hacia don Álvaro se refleja, asimismo, en la primera parte de la comedia de Blas Fernández de Mesa La fundadora de la Santa Concepción, en la que la soberana amenaza a Álvaro de Luna con la muerte:

REINA $\quad$ iArrogante!
No porque vuestra persona
hizo coronar mi frente
os prometáis vanamente
manosear mi corona.
Mas yo altivo, audaz y vano
raya os pusiera, y temor,
si un rato el rey mi señor
pusiera el cetro en mi mano (vv. 2217b-2225).

De forma similar sucede en la obra atribuida a Lope, El milagro de los celos y don Álvaro de Luna, donde la soberana advierte al condestable de que no tendrá reparos en acabar con su vida: "Hoy me mira mal el rey, / mas, don Álvaro de Luna, / otro día querrá Dios / que yo le sepa obligar, / y aqueste fiero pesar / paguéis con la vida vos" (p. 266).

Esta influencia de la soberana en la caída del condestable también se recoge en la comedia Doña Beatriz de Silva, puesto que la soberana se niega a decir al noble dónde está la hermosa dama, a la que ha encerrado en un armario para dejarla morir de inanición y asfixiada ${ }^{7}$, amenazándole con quebrar su trayectoria política si persiste en averiguarlo: "Soy vengativa yo y, si me importuna / vuestro enfado, tal vez por no sufrillo, / puesta al espejo, rompo yo su luna" (vv. 2328-2330).

En Las mudanzas de Fortuna, Lope centra su atención en la caída en desgracia de don Beltrán -privado del rey aragonés-, su subsiguiente exilio y la restitución final de su honor, dignidad y bienes. En este contexto se introduce a Catalina, trasunto histórico de la reina Leonor de Castilla (1307-1359), quien contribuye a la caída del valido y refleja asimismo las tensiones dinásticas entre los hermanastros don Pedro (hijo del monarca Alfonso y su primera mujer, Teresa) y don Alfonso (su hijo) ${ }^{8}$.

El primer personaje en intervenir en la obra es la reina, que da muestras de la tirantez que mantiene con su hijastro don Pedro por cuestiones sucesorias. A través de una larga y agria conversación con este, se va reflejando el carácter sibilino de la reina, quien en su segunda intervención en escena mantiene otro desagradable

7 Según tradición, "la reina la hizo encerrar [a doña Beatriz de Silva] en un cofre, en la villa de Tordesillas, donde permaneció tres días y tres noches sin ingerir alimentos, condenada a morir asfixiada" (Jiménez Sánchez, 2005: 706).

8 La reina Leonor estuvo desposada con Alfonso IV el Benigno, casado en primeras nupcias con Teresa de Entenza, nieta del conde de Urgel; de este matrimonio nace su sucesor Pedro, que asciende al trono como Pedro IV el Ceremonioso. De su segundo matrimonio con Leonor de Castilla nace Fernando, al que dona numerosas posesiones del reino de Valencia, provocando con ello las sonadas protestas de su primogénito Pedro, así como de parte de la nobleza aragonesa y de la población valenciana. Se puede consultar Zurita, Anales de Argón, libro VII. 
diálogo, en esta ocasión con el privado don Beltrán, al que acusa de haber defendido los derechos al trono de don Pedro - primogénito de su esposo y, por ende, legítimo heredero-y de conspirar para dar muerte a su hijo Alfonso:

REINA ¿Pues qué mayor malicia que haber dado
en decir que el Estado Pedro tenga,
y que es justo que venga al heredero
príncipe que primero vino al mundo,
y que porque el segundo se apercibe
a la corona y vive en su esperanza,
antes que espada y lanza lo averigüen
y leyes atestigüen su derecho,
le sosieguen el pecho con veneno?
¿Parécete muy bueno este consejo? (p. 738)

El privado don Beltrán apela a Dios para que sea quien castigue las envidias que están suscitando esas falsas acusaciones contra él y contra su probada lealtad. La soberana, cuya única ambición es ver reinar a su hijo Alfonso, le avisa abiertamente de que va a acusarlo de conspiración ante su esposo para lograr su ejecución: "Pues advierte, / si te mataren, que te doy la muerte" (p. 738). Don Beltrán, que defiende a don Pedro en tanto que es el legítimo heredero, se muestra preocupado ante estas coacciones de la soberana, consciente de que la reina "es mujer, está ofendida. / Son fáciles en creer / y en la venganza prolijas" (p. 739). Si bien es cierto que don Beltrán cae en desgracia debido a estos tejemanejes de la reina, una vez ocupado el trono por don Pedro recupera su puesto y posesiones. La soberana Catalina, por su parte, ya no vuelve a aparecer en escena tras la amenaza proferida contra el privado, sino que es tan solo nombrada en dos ocasiones para hacerse referencia a su exilio: primero, en boca del nuevo monarca; posteriormente, de la dama Leonor, que huye con ella a la ciudad de Valencia.

Menos fortuna política que don Beltrán tiene san Bruno en la tirsiana El mayor desengaño. En esta comedia hagiográfica intervienen dos reinas: una emperatriz de Alemania y una reina de Francia9. De ellas, la que tiene un conflicto con el privado de su esposo es la emperatriz alemana, que aparece en el segundo acto mostrando sus celos y desavenencias matrimoniales -reflejo histórico ${ }^{10}$ - por el interés que manifiesta su marido, el emperador Enrico, hacia una hermosa esclava: "Pero ¿quién fue el soldado / que atrevido tal presa ha presentado / al césar dando causa a mis enojos, / materia a celos y a su amor despojos?" (vv. 1548-1551). La emperatriz, movida por sus irracionales celos, trama una cruenta venganza contra Bruno, al que considera culpable del interés del monarca en la hermosa joven: "Contra Bruno mi sospecha, / de mi venganza cruel / verá efetos, pues que loco

9 Aunque de ninguna de ellas se indica el nombre, si se tiene en cuenta el periodo de vida de san Bruno (10301101), el nombre del emperador alemán Enrico el Cuarto (v. 1682) -no se aporta el del monarca francés-, así como algunos sucesos concretos relacionados con las soberanas, se puede descubrir el personaje histórico del que pretenden ser trasunto: la emperatriz Berta de Saboya (1051-1087), esposa del emperador alemán Enrique IV, y la reina francesa Berta de Holanda (1055-1094), mujer de Felipe I de Francia. Se puede consultar, para más información al respecto, Zúñiga Lacruz (2015).

10 Enrique IV intentó divorciarse de su esposa: "San Pedro Damián, purpurado en 1058 y muerto en 1072, intervino en 1069 para evitar que el emperador se divorciara de Berta de Saboya" (Ávila Seoane, 2013: 36). 
/ buscó celos en mujer" (vv. 1636-1639). Tras alejar el peligro de adulterio de su esposo al concertar la boda entre la esclava y un caballero de la corte, la emperatriz contribuye a enemistar al emperador con Bruno, que cae de su puesto de privado y es expulsado de palacio: "Y a quien vuestra privanza / subió con tan malos medios, / derribad, pues que es indigno / del favor que le habéis hecho", exige la emperatriz a su marido (vv. 2146-2149).

De esta forma, aunque la soberana ejerce un papel secundario, su función en la obra es determinante, puesto que hace ver a Bruno las intrigas y envidias que rodean al poder: ella es la principal responsable de su caída del principal puesto de confianza del rey.

En síntesis, las reinas de estas obras presentan ciertas similitudes:

- Odian a los privados por el poder que atesoran, la influencia que ejercen sobre sus esposos y la confianza que tienen con ellos:

- La reina Isabel de Portugal en las obras mencionadas desconfía del influjo que ejerce sobre su marido don Álvaro de Luna, cuya presencia en la corte le desagrada por estar en deuda con él al haberle erigido en reina. Eliminarlo es la manera más sencilla de zanjar el compromiso e influir sobre su abúlico marido.

- La reina Catalina desea ver en el trono a su hijo Alfonso, a pesar de que el poder le corresponde a Pedro. La lealtad de don Beltrán hacia el legítimo heredero enciende de ira a la soberana, que procura su caída en desgracia para eliminar a uno de los más poderosos defensores de su hijastro.

- La emperatriz alemana monta en cólera al descubrir los amores que profesa su esposo hacia una esclava. La reina focaliza su ira en Bruno, al que considera cómplice de los devaneos amorosos de su marido.

- Intentan deshacerse de los validos exigiendo a sus esposos que los ejecuten o destierren. Isabel de Portugal logra que su marido firme la sentencia de muerte contra el condestable; la emperatriz alemana consigue que Bruno sea desterrado; menos suerte tiene la reina Catalina, que, aunque logra el destierro de don Beltrán para evitar su influencia sobre su marido e hijastro, no puede evitar que este recupere sus posesiones una vez jurado don Pedro como rey de Aragón. A partir de ese momento, es la reina la que se ve forzada a huir.

\subsection{Reina insidiosa que busca la caída del privado por despecho y celos}

En algunas ocasiones, el enfrentamiento entre la reina y el privado se debe a los celos y al despecho: la soberana se enamora del favorito del monarca, que la rechaza por lealtad al soberano y a su amada. Así sucede en El ejemplo mayor de la desdicha y en Comedia del perseguido.

En la primera obra citada interviene la histórica Teodora (500-548 d.C.), esposa del emperador Justiniano I, que es considerada una de las gobernantes bizantinas más influyentes de la historia, y que ha sido caracterizada de dos maneras antitéticas: como santa, tal y como se la considera en la Iglesia ortodoxa, y como mujer diabólica. Por esta última versión opta Mira de Amescua, quien presenta a la emperatriz como una mujer intrigante que manifiesta su doblez en su constante actuación "al paño", reflejo de su carácter traicionero. Junto a la soberana aparecen otros 
personajes históricos: su esposo, el emperador Justiniano, y el general Belisario. A través de ellos, el dramaturgo elabora una tragedia sobre las mudanzas de fortuna, recuperando la leyenda sobre la desventura del privado falsamente acusado por un enemigo -encarnado en esta obra en la emperatriz Teodora- que cae en desgracia ante el soberano.

La emperatriz Teodora, movida por la envidia, manda a tres nobles de la corte acabar con la vida de Belisario, favorito del rey que ejerce una gran influencia sobre él y hacia quien ella sintió cierta inclinación amorosa antes de sus desposorios con Justiniano. No obstante, a pesar de las promesas de riqueza y poder, ninguno de los caballeros ejecuta la orden debido al afecto que profesan hacia el general. Ante esto, Teodora decide ser ella misma la ejecutora de su venganza. Sin embargo, al conocer su marido Justiniano el crimen que trama, decide desterrarla y conferir aún más poder a su favorito. Este, no obstante, renuncia a tanta grandeza, pidiendo que se restituya en sus funciones a la emperatriz, a quien considera su señora. Esta ejemplar acción de Belisario parece producir en Teodora un efecto catártico: "Vencióme la cortesía, [Ap.] / venciéronme los halagos / de su modestia. Ya siento / el pecho desenojado" (vv. 1869-1872). A pesar de estas palabras de la emperatriz, algunos dudan de su cambio, anticipando así la perseverancia en su maldad: "Yo pienso que persevera [Ap.] / en su tirana crueldad", afirma Filipo (v. 1987-1988).

Efectivamente, Teodora no cambia su carácter destructivo: tras la humilde actuación de Belisario, al que envidiaba por el poder acumulado y la influencia sobre su esposo, renace su amor hacia él. La emperatriz, entonces, se declara al general, ofreciéndole entregarse a él y alentándolo a hacerse con la corona. Este, por lealtad al emperador Justiniano y a su patria, así como también por el amor que profesa a su dama (Antonia), rechaza a Teodora. Esta, despechada y herida de celos, trama un último ardid que supondrá la caída definitiva del general: hace creer a su esposo que Belisario intenta seducirla. Para ello intercepta una carta de amor que el general ha entregado a su dama y engaña al emperador haciéndole creer que, en realidad, se la ha escrito a ella.

Justiniano, a pesar de conocer la maldad de la que es capaz su esposa, pero sumiso a su voluntad, cree su engaño y manda sacar los ojos a Belisario. Este, al que todos rechazan, se ve condenado a una vida de mendicidad que derivará poco después en la muerte. Una vez acontecida esta, la amada de Belisario, Antonia, descubre ante el emperador la trama urdida por la emperatriz. Ante esto, deshecho de dolor, Justiniano decide repudiar a Teodora.

La emperatriz, por tanto, actúa injustamente, erigiéndose como tirana al ordenar a tres de sus vasallos que castiguen con la muerte, sin ninguna justificación racional -movida tan solo por la envidia y, posteriormente, por el despecho-, al favorito de su esposo, el general Belisario. Teodora queda, por tanto, reflejada como ejemplo de maldad y figura destructiva, que arrastra a la muerte al privado de su esposo por su irracional cólera.

En la misma línea que la emperatriz Teodora se mueve Casandra en Comedia nueva del perseguido. Esta joven, desposada con el duque de Borgoña-mencionado como rey-, siente un irracional amor hacia Carlos, que disfruta de la especial confianza del monarca y que, tanto por lealtad a él como por amor a su esposa Leonora, rechaza las insinuaciones de la soberana. Esto provoca el despecho de Casandra, que busca dar muerte al favorito de su esposo: "Con cuanta gente hay en casa / intento su muerte hoy" (vv. 1881-1882). 
Cuando el noble Carlos -que ha aguantado pacientemente las insidias de la soberana, incluso el intento de asesinato de su hijo Grimaldico- se resuelve a denunciar ante el duque las pérfidas acciones de su esposa, este decide divorciarse de ella: "Yo repudio la duquesa / ya del marital consorcio / y es mi voluntad expresa / hacer con ella divorcio, / que yo sé que no le pesa" (vv. 3336-3340).

A Casandra, no obstante, sí que le pesa el repudio, puesto que al final de la obra se arrepiente de todos sus actos y pide disculpas a Carlos y a su esposa Leonora: "Al buen Carlos y a Leonora, / pido perdón, perdón pido, / que su humildad me ha vencido, / virtud que a Dios enamora" (vv. 3472-3475). Estos, convencidos del arrepentimiento de la reina, deciden interceder por ella ante el monarca, pero este se niega a modificar su decisión: "Nadie diga mal ni bien, / rey soy y en esto me cierro" (vv. 3454-3455).

Casandra aparece reflejada, por tanto, como un ser pérfido y vengativo, que, ante la actitud virtuosa de Carlos, termina arrepintiéndose de todas sus maldades.

Conforme a este análisis de las soberanas Teodora y Casandra, se puede afirmar que ambas presentan las siguientes semejanzas:

- Se enamoran del favorito de su esposo, pero, al ser rechazadas, truecan sus sentimientos de amor en odio.

- Persiguen con ahínco la muerte del privado: Teodora lo consigue, pues Belisario queda en un estado de indigencia que lo condena a una prematura muerte; Casandra, sin embargo, no logra el propósito de acabar con la vida de Carlos.

- El castigo para ambas soberanas es el mismo: el repudio y destierro. La diferencia estriba en que Teodora no se retracta de lo hecho -y, a pesar de ello, parece que Justiniano podría perdonarla, según relata la dama Antonia-, mientras que Casandra sí parece mostrar un arrepentimiento sincero. Su esposo el duque, sin embargo, no está dispuesto a concederle el perdón, ni tan siquiera a pesar de la intercesión de sus principales víctimas, Carlos y Leonora.

Estas obras teatrales del Siglo de Oro atienden a la relación que se establece entre valido y reina consorte (figuras subordinadas, en principio, al poder del soberano), reflejando, en algunas ocasiones, la relación cordial entre ambos personajes (Hacén y Sultana o santa Isabel y Ramiro, por ejemplo) o la relación conflictiva por cuestiones de índole política o, en ciertos casos, amorosa. En todos estos textos teatrales también está presente el personaje del rey, de menor presencia escénica pero de gran importancia dramática, ya que es a quien le corresponde ejercer de forma efectiva el poder. Se distinguen los siguientes tipos:

- El monarca confía en su intrigante valido en lugar de en su virtuosa esposa. De tal forma sucede en La mejor luna africana, Santa Isabel, reina de Portugal y La adúltera virtuosa. El rey condena a muerte a su mujer, aunque la verdad sale a la luz antes de la ejecución.

- El rey -por abulia, ceguera amorosa o para evitar problemas (resignación)confía en su intrigante esposa en lugar de en su virtuoso valido. Son ejemplo de ello las obras sobre Isabel de Portugal y Castilla, Las mudanzas de Fortuna, El mayor desengaño y El ejemplo mayor de la desdicha. El soberano dicta sentencia contra su privado (destierro o castigo físico). 
- El monarca confía en su virtuoso valido y desconfía de su intrigante esposa: es el caso de Comedia nueva del perseguido. El rey repudia y destierra a la soberana.

Las diversas relaciones que se establecen entre validos y reinas en las obras analizadas pueden entenderse como lecciones sobre el ars gubernandi, pues se presentan modelos positivos y negativos de ejercicio del poder tanto en la categoría de privados como en la de reinas. A través de estos personajes se censuran las acciones que nacen de envidias, recelos e ingratitudes, y se ensalzan las realizadas por el bien de la patria, basadas siempre en la lealtad y la justicia.

\section{Obras citadas}

Arellano, Ignacio, "El poder y la privanza en el teatro de Mira de Amescua", en Agustín de la Granja y Juan Antonio Martínez Berbel (eds.): Mira de Amescua en candelero, I, Granada, Servicio de Publicaciones de la Universidad de Granada, 1996, pp. 43-64.

Ávila Seoane, Nicolás, "La data en los diplomas del emperador Enrique IV y de su émulo Alfonso VI de León", Documenta \& Instrumenta, 11 (2013), pp. 9-42.

Carrasco Urgoiti, María Soledad, "En torno a La luna africana, comedia de nueve ingenios", Papeles de Son Armadans, 32 (1964), pp. 255-298.

Fernández de Mesa, Blas, La fundadora de la Santa Concepción: comedia en dos partes, ed. Nancy K. Mayberry, New York, Peter Lang, 1996.

Jiménez Sánchez, Antonio Jesús, "Beatriz de Silva y la Inmaculada Concepción. Orígenes de una orden", en Francisco Javier Campos y Fernández de Sevilla (coord.): La Inmaculada Concepción en España: religiosidad, historia y arte, I, Madrid, Real Centro Universitario Escorial-María Cristina, 2005, pp. 691-709.

Martínez de Meneses, Antonio y otros ingenios, La mejor luna africana, Madrid, Antonio Sanz, 1733. Ejemplar de la BNE: T/5154.

Mira de Amescua, Antonio, El ejemplo mayor de la desdicha, ed. Maria Grazia Profeti, en Teatro completo, I, Granada, Universidad de Granada-Diputación de Granada, 2009, pp. 207-302.

- La adúltera virtuosa, ed. Juan Manuel Villanueva Fernández, Madrid, MEC-UNED, 1998.

- La adversa fortuna de don Álvaro de Luna, ed. Miguel González Dengra y Concepción García Sánchez, en Teatro completo, VI, Granada, Universidad de Granada-Diputación de Granada, 2006, pp. 117-225.

Pedraza Jiménez, Felipe B., "Rojas Zorilla ante la comedia de santos: Santa Isabel, reina de Portugal", en Marc Vitse (coord.): Homenaje a Henri Guerreiro: la hagiografía entre historia y literatura en la España de la Edad Media y del Siglo de Oro, Madrid, Iberoamericana-Vervuert, 2005, pp. 967-983.

Peale, C. George, "Comienzos, enfoques y constitución de la comedia de privanza en la Tercera parte de las comedias de Lope de Vega y otros auctores", Hispanic Review, 72.1 (2004), pp. 125-156.

Pérez de Hita, Ginés, Guerras civiles de Granada [1595], ed. Paula Blanchard-Demouge, Granada, Universidad de Granada, 1999 (Edición facsímil de 1913).

- Guerras civiles de Granada [1595], ed. Enrique Suárez Figaredo, Madrid, Austral, 1975. Rojas Zorrilla, Francisco de, Santa Isabel, reina de Portugal, ed. Elena Arenas Cruz, en Felipe B. Pedraza Jiménez y Rafael González Cañal (eds.): Obras Completas. Prime- 
ra parte de comedias, III, Cuenca, Universidad de Castilla-La Mancha, 2011, pp. 11-127.

Roncero López, Victoriano, "El perfecto privado en dos comedias de Tirso: Privar contra su gusto y Cautela contra cautela", en Mariela Insúa y Felix K. E. Schmelzer (eds.): Teatro y poder en el Siglo de Oro, Pamplona, Servicio de Publicaciones de la Universidad de Navarra, Colección BIADIG (Biblioteca Áurea Digital), 18/Publicaciones Digitales del GRISO, 2013, pp. 199-213.

Sáez, Adrián J., "De la privanza en Calderón: Los cabellos de Absalón y La hija del aire", Bulletin of Spanish Studies, 92.2 (2015), pp. 167-177

Tirso de Molina, Doña Beatriz de Silva, ed. Manuel Tudela, en Comedias completas. Cuarta parte de comedias, I, Pamplona, Griso-Instituto de Estudios Tirsianos, 1999, pp. 833-989.

- El mayor desengaño, ed. Lara Escudero Baztán, en Tirso de Molina. El mayor desengaño y Quien no cae no se levanta (dos comedias hagiográficas), Pamplona, GRISO, 2004, pp. 171-300.

Tyler, Richard W., “Algunas versiones de la leyenda de la Reina Sevilla en la primera mitad del Siglo de Oro", en Jaime Sánchez Romeralo y Norbert Poulussen (coords.): Actas del II Congreso Internacional de Hispanistas (1965), Nimega, Instituto Español de la Universidad de Nimega, 1967, pp. 635-641.

Vega, Lope de, Comedia del perseguido, ed. Silvia Iriso y María Morrás, en Comedias de Lope de Vega, I-1, Lleida, Milenio, 1997, pp. 255-458.

- El milagro de los celos y don Álvaro de Luna, ed. Marcelino Menéndez Pelayo, Madrid, Atlas (BAE, 213), 1968, pp. 237-271.

- Las mudanzas de Fortuna, ed. Jesús Gómez y Paloma Cuenca, en Comedias. Lope de Vega, XIV, Madrid, Fundación Castro-Turner, 1998, pp. 677-776.

Zúñiga Lacruz, Ana: Mujer y poder en el teatro español del Siglo de Oro: la figura de la reina, 2 vols. Kassel, Reichenberger, 2015.

Zurita, Jerónimo: Anales de Aragón, ed. Ángel Canellas, Zaragoza, Institución Fernando el Católico. En línea: http://ifc.dpz.es/recursos/publicaciones/24/48/ebook2473_3.pdf(consulta: 6/6/2018). 